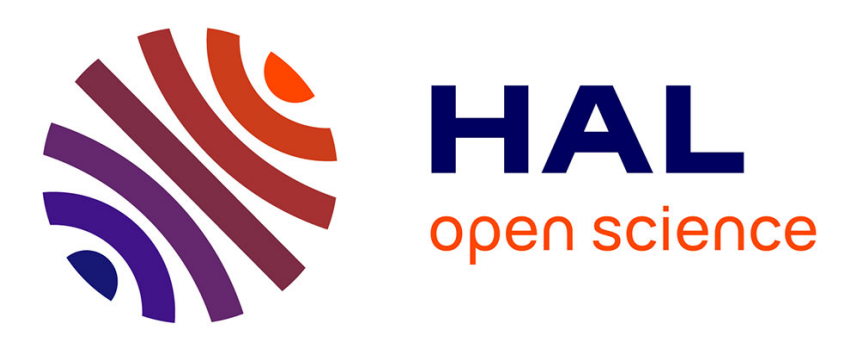

\title{
A cross-scale models interoperability problem: the Plate-Form(E)3 project case study
}

\author{
Alexis Aubry, Jean Noel, Daniel Rahon, Hervé Panetto
}

\section{To cite this version:}

Alexis Aubry, Jean Noel, Daniel Rahon, Hervé Panetto. A cross-scale models interoperability problem: the Plate-Form(E)3 project case study. 3rd industry Applications and Standard initiatives for Cooperative Information Systems for Interoperable Infrastructures, Sep 2013, Graz, Austria. pp.57-61. hal-00850146

\section{HAL Id: hal-00850146 \\ https://hal.science/hal-00850146}

Submitted on 4 Aug 2013

HAL is a multi-disciplinary open access archive for the deposit and dissemination of scientific research documents, whether they are published or not. The documents may come from teaching and research institutions in France or abroad, or from public or private research centers.
L'archive ouverte pluridisciplinaire HAL, est destinée au dépôt et à la diffusion de documents scientifiques de niveau recherche, publiés ou non, émanant des établissements d'enseignement et de recherche français ou étrangers, des laboratoires publics ou privés. 


\title{
A cross-scale models interoperability problem: the Plate- Form $(E) 3$ project case study
}

\author{
Alexis Aubry ${ }^{1,2}$, Jean Noël ${ }^{3}$, Daniel Rahon ${ }^{4}$, Hervé Panetto ${ }^{1,2}$ \\ ${ }^{1}$ Université de Lorraine, CRAN, UMR 7039, Campus Sciences, BP 70239, \\ Vandœuvre-lès-Nancy Cedex, 54506, France \\ ${ }^{2}$ CNRS, CRAN, UMR 7039, France \\ \{alexis.aubry, herve.panetto\}@univ-lorraine.fr \\ ${ }^{3}$ CETIAT, 25 Avenue des arts, BP 52042, 69603 Villeurbanne, France \\ jean.noeldcetiat.fr \\ ${ }^{4}$ IFP Energies nouvelles, 1 \& 4 avenue de Bois-Préau, 92852 Rueil-Malmaison, France \\ daniel.rahondifpen.fr
}

\begin{abstract}
This paper presents the Plate-Form(E)3 project which is funded by the French National Research Agency (ANR) as a case study highlighting cross-scale models interoperability problems. This project involves public and private French organisations. It deals with the specification of a software platform for computing and optimising the energetic and environmental efficiency for industries and territories. Its aim is the integration of specialised tools for analysing sustainability of any processes. One important topic addressed by this project concerns the interoperability issues when interconnecting these tools (for modelling, simulating, and optimising) into the platform at different modelling scales (territory/plant/process/component). This paper proposes to highlight the interoperability issues led by the heterogeneity of the related tools in the energetic and environmental efficiency context.
\end{abstract}

Keywords: interoperability, energetic and environmental efficiency

\section{From energy and environmental efficiency needs to cross- scale models interoperability needs}

The current context of increasing scarcity of fossil fuels and the associated price volatility strongly encourage our society for energy saving. Although significant efforts have been made in the industrial sector since 1973, according to estimation from the French institute $\mathrm{CEREN}^{1}$, the potential power saving could be up to $12 \mathrm{Mtoe}^{2}$ (about $23 \%$ of energy consumption in the industrial sector). These savings could be made on the following basis:

\footnotetext{
${ }^{1}$ CEREN, French Centre for Studies and Economic Research on energy.

${ }^{2}$ Mtoe $=$ Million Tonnes of Oil Equivalent

adfa, p. 1, 2011.

(C) Springer-Verlag Berlin Heidelberg 2011
} 
- About $2 / 3$ of the savings can be made on plants using local optimisation approach, using conventional or experimental technologies.

- The remaining $1 / 3$ of the savings can be achieved by conducting cross-cutting actions, using technology for recovery and transport of residual energy.

The local optimisation approach (process/plant scale) is already extensively studied, while the global optimisation approach (territorial area) is not addressed in the literature. In fact, it does not exist any tool able to achieve a cross-scale optimization of energy and environmental efficiency. The Plate-Form(E)3 project proposes to address this problem.

\section{The Plate-Form $(E) 3$ project}

The ANR Plate-form(E) $3^{3}$ project: Digital Platform for computation and optimization of Energy and Environmental Efficiency at different scales for industry (component/process/plant/territory) must contribute to the optimization of energy and environmental efficiency of industry and territories. Plate-form(E) 3 will be realized by a prototype for assessing the impact of new technologies on a large scale. This framework will propose the integration of any energy sources and sinks across the territory, seeking potential interconnections between industries (territory scale), to optimise process efficiency (plant/process scale) and to facilitate the optimal design of new technologies (component level).

This prototype will enable validating the concept through different scenarios that must be defined by end-users. We can cite as potential end-users of the platform industrials such as Lafarge, INEOS, Arcelor Mittal who want to reduce their energy and environmental impact.

The platform will interconnect some existing tools (open-source or proprietary) implementing different specialised methods, models and algorithms. The issue of interoperability is thus important.

\section{Interoperation problems and scientific questions}

The tools that must be interconnected in Plate-Form(E)3 do not operate at the same scale, with the same business knowledge and on the same models but they must always be able to share information and models that they produce, ensuring the overall coherency of the whole. That means that these tools must be interoperable. [1] defines interoperability as the ability of a collection of communicating entities to (i) share specified information and (ii) operate on that information according to a shared operational semantics (iii) in order to achieve a specified purpose in a given context.

The above context will be defined through three generic scenarios that must be realised within two classical interoperability levels (technical and conceptual) [2]. Some

3 http://www.agence-nationale-recherche.fr/en/anr-funded-

project/?tx_lwmsuivibilan_pi2[CODE]=ANR-12-SEED-0002 
scientific questions then arise when intersecting those scenarios with the interoperability levels.

\subsection{Generic scenarios}

In order to highlight the underlying problems in setting interoperation between the specialised tools for modelling physical systems and their optimisation, it is important to identify the generic scenarios that realize this interoperation. We have identified the following scenarios: cross-scale interoperation, cross-domain interoperation, crossfeature interoperation (see Fig. 1).

1. Cross-scale interoperation: the different scales concern the component (optimal design of new technologies), the process/plant (optimization of energy efficiency) and the territory (optimization of potential interconnections between industries). The tools that will potentially be connected with the platform will be used at these different scales, producing models that need to be exchanged compromising the overall performance.

2. Cross-domain interoperation: for modelling/simulating/optimising the physical systems through the platform, users use knowledge and domain-dependant tools that are specialised. Thus experts' knowledge covers broad areas of physics for modelling thermal, thermodynamics, chemistry and energetics processes. We must also add the experts' knowledge related to optimization.

3. Cross-feature interoperation: physical systems modelled in Plate-Form(E)3 will be simulated and optimized through these models. Tools for modelling, simulation and optimization tools need to be interconnected.

Fig. 1. Plate-Form(E)3 interoperation framework

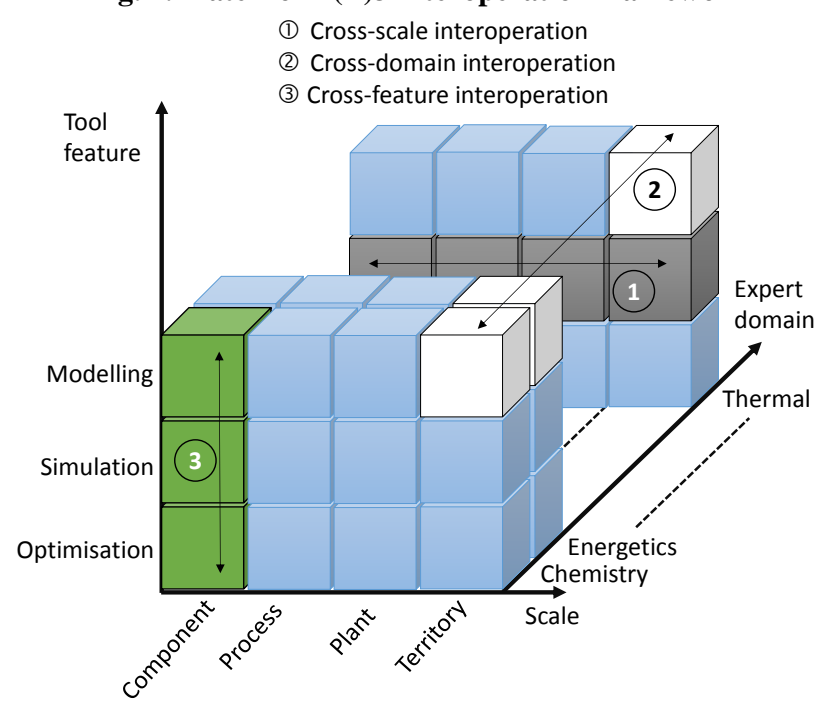




\subsection{Interoperability levels}

For making the previous scenarios effective, there exist some barriers (conceptual, technological and organisational) that define levels of interoperability to be studied. While organisational barriers are an issue mainly from governmental and privacy perspectives, the project will focus on technical and conceptual barriers defined in [2] as follows:

- Technical barriers are related to the incompatibility of information technologies (architecture \& platforms, infrastructure...).

- Conceptual barriers are related to the semantic mismatches of information to be exchanged. These barriers concern the modelling at the high level of abstraction.

\subsection{Scientific questions and discussion}

For highlighting the scientific questions linked to the Plate-Form(E)3 project, we propose to intersect the different generic scenarios with the interoperability levels. Technical interoperability problems appear in each scenario. Solving these technical barriers is now easier and partly achieved by standard techniques and implemented interfaces. We can cite, for instance, XML (eXtensible Mark-up Language) and linked applications: SOAP (Simple Object Access Protocol) and WSDL (Web Services Description Language). We must therefore assess whether the candidate tools for integration into Plate-Form(E) 3 use existing standards $\left(\mathrm{CAPE}-\mathrm{OPEN}^{4}, \ldots\right)$ or we must define such a standard. When connecting a new tool, we must be able to assess quickly its ability to interoperate with Plate-Form(E)3 at the technical level.

Conceptual interoperability problems concern:

- for the cross-scale interoperation scenario, the dynamics and the granularity of the used models that are not the same. Indeed, the models have not the same time scale when considering a territory or a component. Moreover, the different models represent heterogeneous aggregates of information depending of the scale of the modelled system (from territory to component). It is therefore necessary to formalize and finally assess the correlation between models outputs at a given scale and their use as inputs at another scale (with the same tool or not).

- for the cross-domain or cross-feature interoperation scenarios, the knowledge of several specific domains that are managed by the different tools to be connected through the platform. These heterogeneous knowledge produce semantically heterogeneous models that must be exchanged, stored, processed consistently with the purposes for which they have been built. Moreover, this raises the issue of the a priori evaluation of the ability to exchange ad-hoc models (related to a specific domain or a particular tool fea-

\footnotetext{
${ }^{4}$ http://www.colan.org
} 
ture) without knowing in advance the tools that will be connected to the platform to process these models (and thus the business semantics of the related models that are shared through the platform).

We propose in Table 1 below, a synthesis of the highlighted scientific questions that raised from the scenarios.

Table 1. Table Interoperation Scenario/Interoperability levels

\begin{tabular}{|c|c|c|}
\hline $\begin{array}{l}\text { Interoperability level } \\
\text { Interoperation scenario }\end{array}$ & Technical level & Conceptual level \\
\hline Cross-scale interoperation & \multirow{3}{*}{$\begin{array}{l}\text { Representation of } \\
\text { knowledge }\end{array}$} & $\begin{array}{l}\text { Assesment of the dynamics and } \\
\text { granularity compatibility of models }\end{array}$ \\
\hline Cross-domain interoperation & & A priori evaluation of semantic \\
\hline Cross-feature interoperation & & interoperability between models \\
\hline
\end{tabular}

Acknowledgement.

This work has been partially funded by the program SEED 2012 from the French National Agency for Research ANR in the frame of the Plate-Form(E)3 project.

\section{References}

1. D. Carney, D. Fisher and P. Place. Topics in Interoperability: System-of-Systems Evolution. echnical Note, University of Pittsburgh, Software Engineering Institute, 2005.

2. INTEROP, Enterprise Interoperability-Framework and knowledge corpus - Final report, INTEROP NoE, FP6 - Contract n 508011, Deliverable DI.3, May 21st 2007. 